\title{
Evidence Based Health Demographic Assessment of URIRI Sub-County in Migori County, Kenya
}

Njeru S. Kagoiyo ${ }^{1^{*}} \mid$ Mburu S. Wanjiku ${ }^{2}$ Sabinah W. Kagoiyo ${ }^{3}$

${ }^{1}$ Lecturer, Kirinyaga University, P.O. Box 143-10300, Kerugoya, Kenya,

${ }^{2}$ Kirinyaga University, P.O. Box 143-10300 Kerugoya

${ }^{3}$ Kirinyaga County Referral Hospital, P.O Box 24-10300, Kerugoya, Kenya

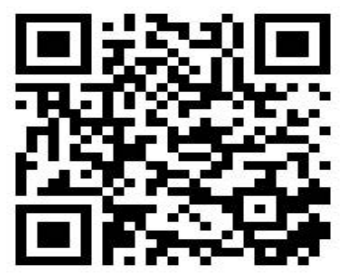

\begin{abstract}
:
Objective: To assess health demographic profile of Uriri sub-County in Migori county, Kenya.

Study Design: Prospective study using a questionnaire

Study Setting: Uriri Sub-County in Migori County, Kenya

Study Participants/Subjects: Mothers with children under the age of five years. This was done purposely in order to capture the relevant information required on maternal, child health and other areas.

Results: The survey revealed many gaps that needed interventions both locally and from the National level. The literacy levels were still wanting with $70 \%$ not going past tertiary levels of education. This had an impact on diverse areas socio-economically starting with family life with children occupying $56 \%$ of the total house hold composition. This led to low literacy levels. The finding also revealed poor food security situation in Uriri constituency, with over $70 \%$ admitting they did not have enough food stocks in their households to last them till the next harvest. Three hundred and forty one $(50.3 \%)$ mothers did not deliver in the available health facilities and $40.7 \%$ did not attend Antenatal Clinics.
\end{abstract}

Conclusion: Literacy especially amongst women is quite important in the making of a community, even though both sexes play an important part in passing education down their generations. Lack of education and information on pertinent issues of family care led to increased numbers of children which directly impacted on the overall population. Lack of financial capacity and economic empowerment was part of the reason for food insecurity in the area. The study showed that half of the women in Migori County do not visit the health facilities available in the county. This is in spite of the Government providing health resources in the region. 


\section{1 | INTRODUCTION:}

$\mathrm{P}$ overty is defined as the inability to access basic human needs by segments of the population. The second poverty report of June, 2000 identifies the poor in terms of food poverty, hard core poverty and absolute poverty. Fifty eight per cent (58\%) of the sub-county population is in absolute poverty whereas a large percentage experience food poverty (Strategic Plan, 2005-2010) (1) . Mothers with children under the age of five years were interviewed in this study. This was done purposely in order to capture the relevant information required for the research, this touched on maternal, child health and other areas which were essential for a complete baseline report.

\section{2 | METHODOLOGY:}

Study Setting: The area of baseline survey was in Uriri constituency which constitutes five wards; Central Kanyamkago, West Kanyamkago, East Kanyamkago and South Kanyamkago with two divisions; Oyani and Uriri, each constituting 3 sublocations; Oyani which comprises of Bware, Thim Jope and Arambe; while Uriri has East KawereRateng', Katieno 2 and Kawere 2B in Migori county formerly known as Migori District is located Southwest of Kenya and has a population of 1,028, 579 and an area of 2,005 $\mathrm{km}^{2}$ (Census, 2009) (2) . The county has four local authorities namely; Migori town with a population of 46, 576 with an urban population of 31,644 , Awendo town with a population of 93, 387, Rongo town with 64, 528 and Migori urban with 310, 406.

Study Design: Cluster sampling was used to come up with the two divisions while systematic random sampling was used to in order to come up with the 6 villages while, purposive sampling was applied in order to determine the kind of households to target hence there was no pre-determined list for choosing the households

Sampling Frame: The sampling frame was households with children under the age of five years.
Sampling Size: The sample size was determined by a calculation and the number of households and each interviewer was to cover a total of 13 households by the end of day two. A total of 21 interviewers who were also Community Health Workers were divided into seven groups such that a group of about three members were taken to each site for the interviews after their training. There was assistance by a few learned community members. A total of 676 Households were interviewed.

Hence sample size $=52 \times 13=676$ households

Data Collection Tool: The baseline survey tool was drafted by the first author and comprised of seven thematic areas that were used to collect information. This also helped in forming groups which were used in the data collection;

1. Demographic data

2. Maternal Health

3. Child Health

4. House hold participation

5. Environmental health

6. Morbidity

7. Mortality

Data collection took place for two days on $14^{\text {th }}$ and $20^{\text {th }}$ February, 2016 using a questionnaire. Data was collected in 13 households. The enumerators also assisted in translations from English to Swahili for those who did not understand English

Data Cleaning: Data cleaning was conducted with the help of our supervisors who made sure that the questionnaires did not have mistakes and that the

Supplementary information The online version of this article https://doi.org/10.15520/jcmro.v3i08.325 contains supplementary material, which is available to autho-rized users.

Corresponding Author: Njeru S. Kagoiyo

Lecturer, Kirinyaga University, P.O. Box 143-10300, Kerugoya, Kenya,

Email: skagoiyonjeruh@gmail.com 
information collected were valid and recorded in the questionnaire.

Data Entry Process: Data entry process began with manual tallying of variables on tally sheets. Individual tallies were recorded followed by group tallying. All the 7 group tallies were consolidated to form a master tally sheet that was to be used by the entire lot.

Data Analysis: Data were analyzed from all groups, hence this report focuses on analysis covered under demographic profile;

- Age and sex composition

- Males and females

- House hold composition

- Relationship to the household head

- Other household characteristics

- Level of education, housing type,

- Registered births,

- Religious affiliations

- Food security,

- Antenatal visits and

- Delivery in Health Facility

\section{3 | RESULTS:}

Demography studies characteristics of human populations, such as size, growth, density, distribution, and vital statistics. It is a very important branch of science that enable us understand humans in terms of increase, distribution and concentration.

\section{Age and Sex composition:}

This is the basic characteristic of a population; every setup has different age and sex composition which gives the proportion of males and females in each

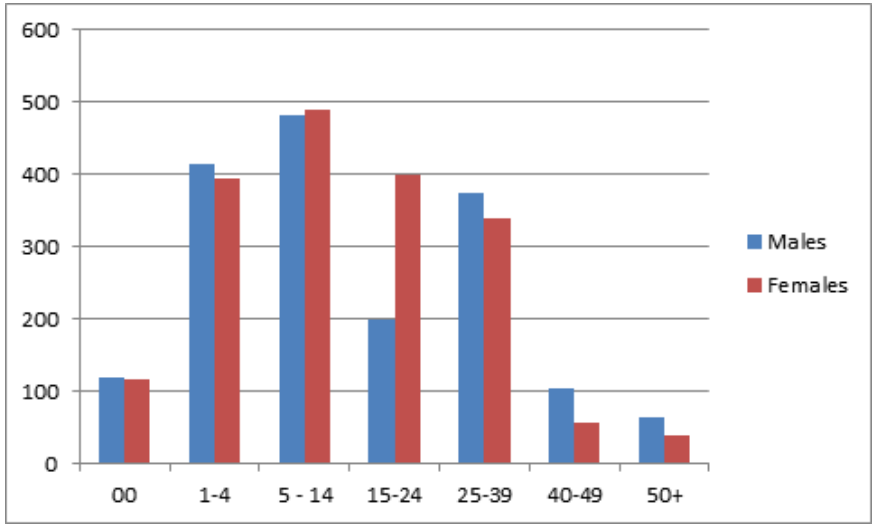

FIGURE 1:

age group. All this information can have a considerable impact on the population's social and economic situations both at present and in the future.

The age distribution across all the 676 households was captured as shown in the graph. The infants, under the age of one year were; males with almost $7 \%$ while the female were slightly lesser with $6 \%$. This could be explained by other factors that need exploration.

This trend is also seen in the under five year olds with male children exceeding the females by $2 \%$ giving a total of $45 \%$ for both. There is slight change with the numbers beginning to reduce with the female children ages between 5-14 gaining numbers by $15 \%$.

The numbers tremendously dropped for both males and females for the ages 15-24 but the females were still high with $21 \%$. There is a slight increase of the males from $25-50+$ years with numbers exceeding the females with a big margin at $30 \%$ compared to females of the same ages across who have $23 \%$. There seem to be more women of reproductive ages between the ages of 14 and 24 years and they reduce in numbers as their ages increase with time.

The male/female ratio $=$ Total no. of male $\times 100=$ $1756 \times 100=95.43=95$

Total no. of females 1840

$=95 / 100$

The baseline survey shows the percentage of females reduced to $49 \%$ from $52 \%$ according to the Migori County fact sheet (2010). This gives a reverse trend from the usual national figures where the female have a higher percentage than men. 


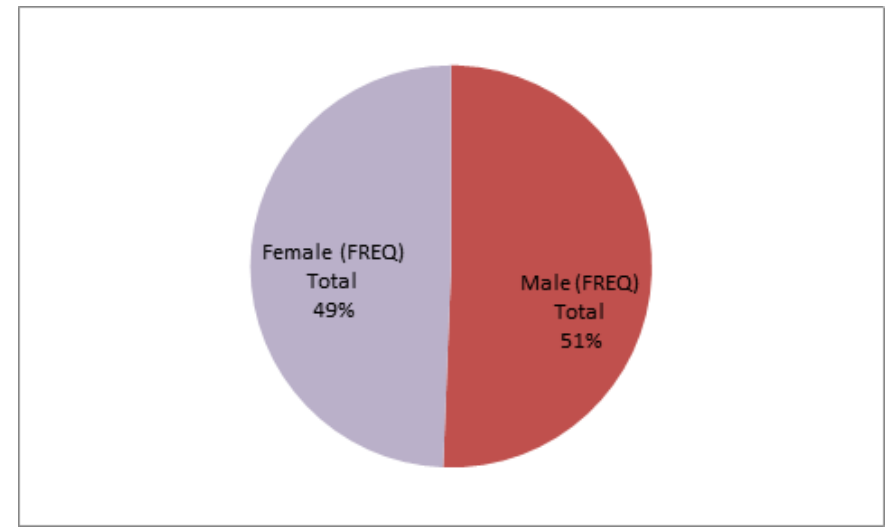

FIGURE 2: Percentageof females to males

\section{House hold composition}

A household is one or more persons who occupy a single housing unit (Population Handbook, 2004). In some instances apart from having persons related by birth or marriage, some households can have unrelated persons or even cases of adoption.

By knowing the number of people who live in a household and the number of households, then we can calculate the average size of households.

Households and families are the basic units in which most people live. The trends in number, type and composition of the households are important when it comes to planning and policy making. Most services in urban centres or counties are offered as per households not as per individuals.

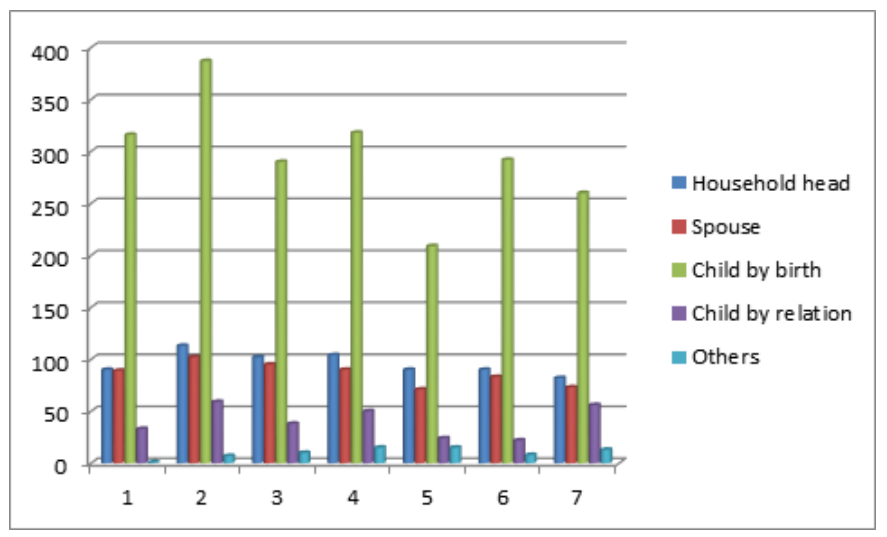

FIGURE 3:

According to the baseline survey, there are more children by birth comprising of $56 \%$ of the household makeup, they accounted for the larger population in most households.
In some areas the numbers of household were almost same as their spouses but in most cases they were more than their spouses. Child by relation is at $8 \%$ compared to child by birth that comprise of more than half the household population. Children by other relation mostly due to other factors are the least with almost $2 \%$.

Average household size $=$ Number of persons living in households

Total households

Average household size $=3696$

676

$=5.4674556=5.5=6$

Hence the average number per household is therefore at 6 members per unit. This could be dangerous considering the fact that most households are not performing well in terms of socio-economic capacity, meaning they could be burdened.

\section{Other household characteristics}

\section{Educational attainment of the house hold popula- tions}

Education is the imparting of knowledge and skills in transformation of individuals by changing their attitudes and practices for a positive change and development.

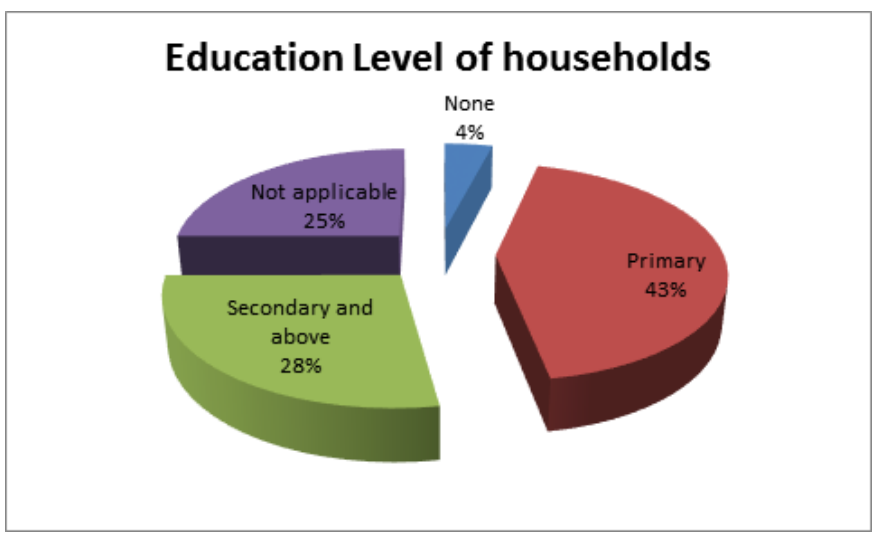

FIGURE 4:

The baseline showed a big percentage of $43 \%$ of most households are primary level individuals. This 
also captures the household heads who only a few managed some level of secondary education but very few numbers reached tertiary levels. The Kenya literacy bureau (2008) (3) , aims to ensure that $90 \%$ of the population is learned up to tertiary level, but according to the baseline, the literacy levels are still low.

Twenty five per cent (25\%) comprised of younger children who are under school age of 6 years and were not attending school. Four per cent (4\%) of the population did not have education and consists of adults.

\section{Housing type}

One of the basic human requirements is good shelter. If housing has enough space, well lit and sufficiently ventilated then issues of health and social norms can be well addressed.

Permanent houses are made up of long lasting materials comprising of cement and iron sheets while semi-permanent have walls made of mud and roof of iron sheets and the floor can either be earth or cemented. Temporary houses are those ones made from lesser materials which do not have a long life span; the walls and the floor are both mud and the roof is made of thatch grass.

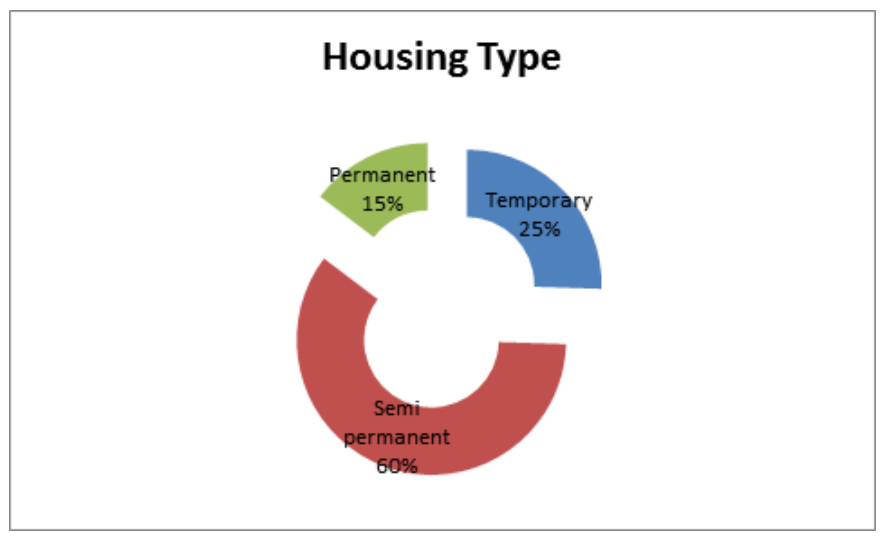

FIGURE 5:

The findings revealed that $60 \%$ of the houses are semi-permanent, $25 \%$ temporary while only very few were permanent. This clearly shows the economic ability of the population meaning they are not well financially placed to afford good and appropriate housing.

\section{Vital statistics - Birth Registration}

Registration of vital statistics is very important for a country as this will help in information on the number of deaths and births; hence planning in advance for interventions and budget inclusions.

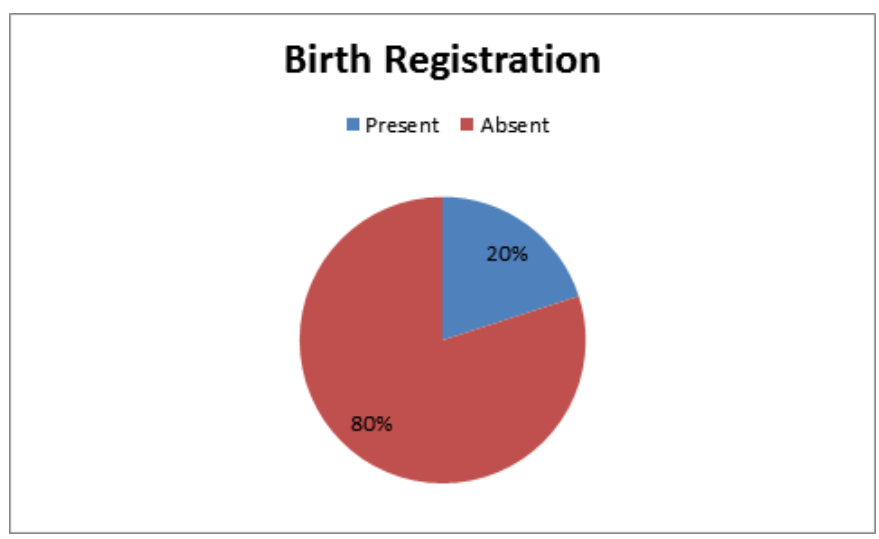

FIGURE 6:

From the baseline findings, $80 \%$ of the households with under five years old did not have birth certificates or could not trace them. Only $20 \%$ had them at the time of visit.

\section{Religious affiliation}

Spirituality and religion play a very important role in the making and shaping of a people morally and uprightly. Healing of communities after an episode of conflict is vital for continuous co-existence and development.

Lack of spirituality and religion may also lead to breakdown of social norms and family units.

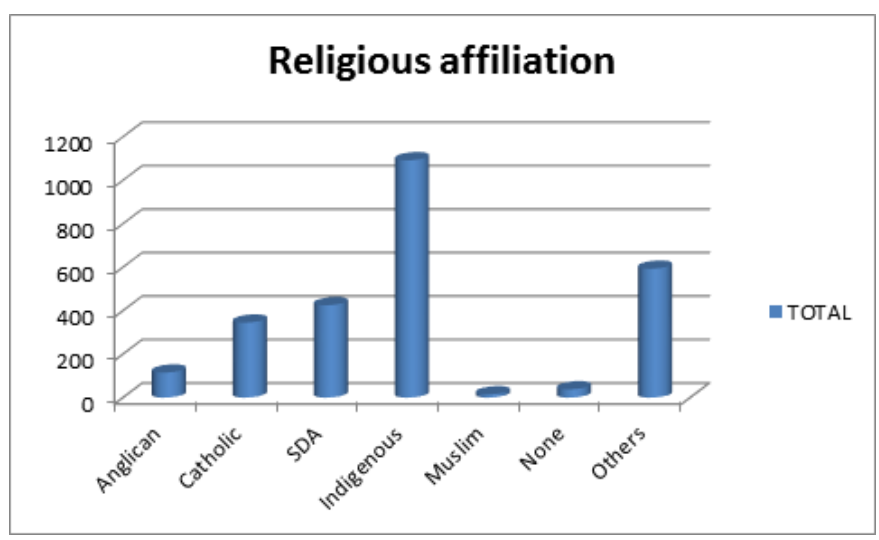

FIGURE 7: 
Most people were found to be worshipping in the indigenous churches that is, this include spiritual churches which are of the local origin. This has taken $50 \%$ of the proportion, followed by Seventh Day Adventist with $20 \%$ while others take up the remaining proportion of $8 \%$. Hence most people worship with the new found churches in the Uriri constituency.

\section{Total Land size}

Land is a natural resource on which grows natural vegetation and on which human beings co-exist. Without land, it means one might be unable to meet some of the basic needs such as education, food, settlement and economic development.

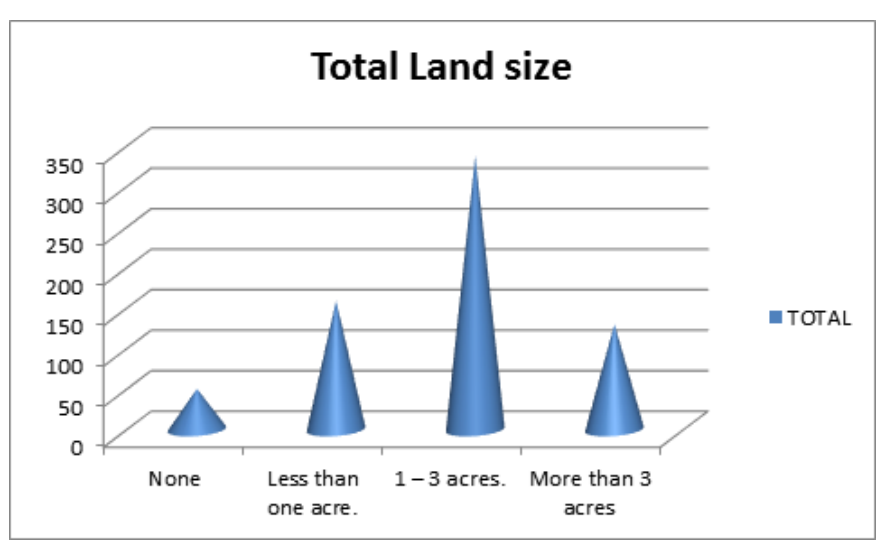

FIGURE 8:

Most of the families had up to three acres of land. This comprised of almost $50 \%$ of the population, who occupy almost a quarter of an acre where they have built residential houses and made compounds. However there are those families with less than one acre and consist of $33 \%$ while those who did not have land were $7 \%$. A few in the population had more than 3 acres.

\section{Size of land currently under cultivation}

Food security is very important for the survival of individuals. Without enough land that is arable, may lead to starvation and eventual ill-health. There will also be economic stagnation since there are no economic activities that stimulate productivity within the community.

Almost half of the families had their land of three acres under cultivation. This took $48 \%$ of the total

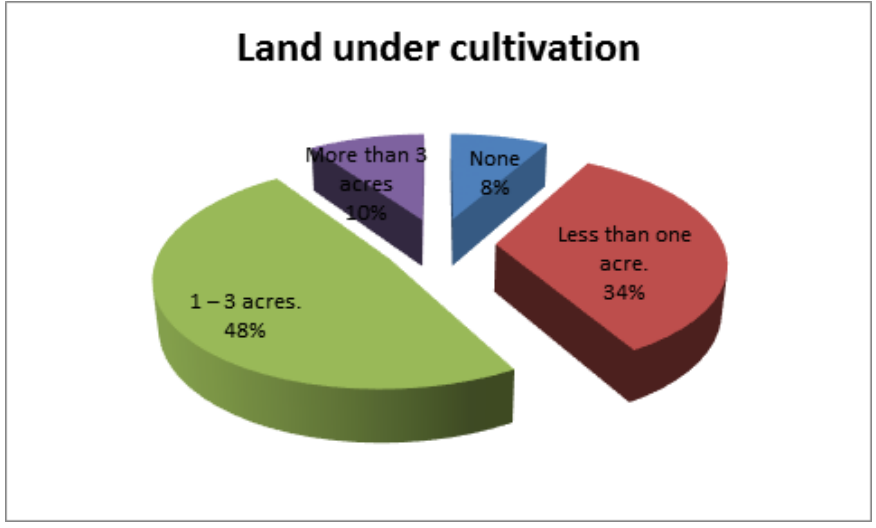

FIGURE 9:

while families who are tilling less than one acre were $34 \%$ while those who had more than three acres tilled $10 \%$ of their land. This means that food security situation in Uriri constituency is not good as the less land is being put to use. This testifies why most households did not have cereals present at the time of visit.

\section{Cereals present}

The baseline shows $50 \%$ of the households depended on other sources to get food. This included purchasing from the shops and markets the cereals they required for their daily survival. Only a quarter admitted they had cereals present in their households but still was not enough to last till the next harvesting season.

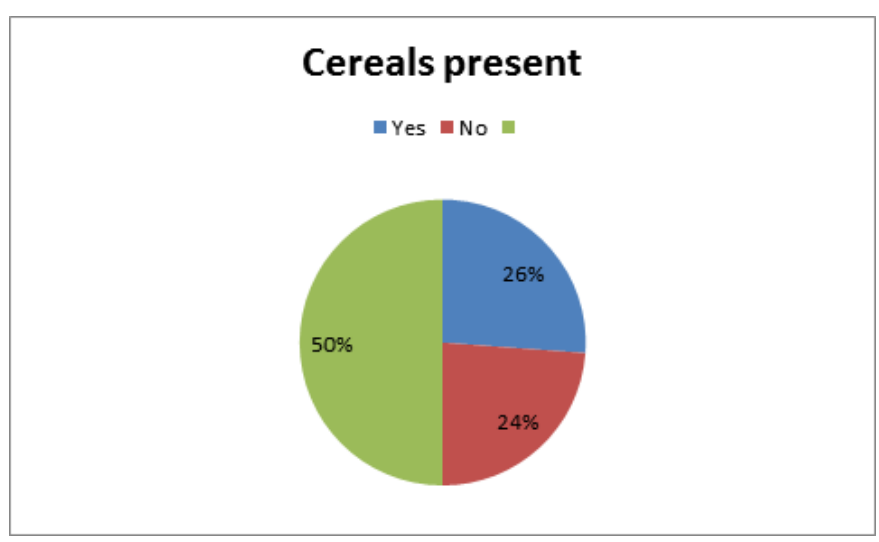

FIGURE 10:

The general situation of food security is wanting as this might soon be catastrophic if there is nothing done to intervene. 


\section{Antenatal visit}

Respondents indicated that almost half, 276(40.7\%) of mothers do not attend ANC clinics for their health services as shown below

\section{Health facility delivery}

More than half $(50.3 \%)$ of the mothers did not deliver in the provided health facilities in Migori county.

\section{4 | DISCUSSION:}

Having been involved in many such undertakings and having had enormous experience in many partnership sites, there has been the identification and training of community health workers who are instrumental in the realization of improved health at the household level.

Generally, this report has highlighted the demographic profile of Uriri constituency in Migori County. According to the County fact sheet in the Migori County development plan of 2009/2019 (4), males cover $48 \%$ of the overall Migori County while females comprise of $51 \%$, this almost coincides with the Uriri constituency's findings. There is a large proportion in the age dependant bracket which in the long run may effect on the general economy. The fewer numbers of the neonates compared to those of between $1-4$ years, this sends a signal meaning an intervention needs to be put down in order to save the lost numbers and improve the situation. Even though the females seem to be more in numbers but their population reduces as they mature which is also a sign that some interventions should be laid down to improve maternal health as this could be due to coupled reasons.

On the level of literacy, it is still very low compared to the required coverage of $90 \%$ with almost half the population managing primary level only. This impacts a lot on things touching across health and economic ability of the households. The more an individual is learned, the better the standards of living. Literacy should target the both with much emphasis on the female since they are the pillars of most households. An enlightened woman means enlightened generation.

According to the Migori fact sheet number of children per woman is at 7.1 while the baseline revealed a reduction to an average number of 5 per woman per household. Even though this has slightly gone down but the fertility rate is still high. On registration of births, generally is poor with $80 \%$ not having birth certificate for their children, could be that the mothers might be ignorant and could not be having information on the importance of registering the births. The number of children by birth is very high capturing $56 \%$ of the households; it is an indicator that an intervention on the side of family planning needs to be put down. The number of people in a household could portend an increase in poverty given the poor socioeconomic status in Migori at large.

Food security situation is very poor with more than $70 \%$ not having enough food supplies stocked in their households till the next harvesting season. This could be due to coupled reasons such as erratic rainfall patterns, lack of technological advice or lack of finances to carter for the whole farming costs.

Many mothers $(50.3 \%)$ did not deliver in the available health facilities in Migori while $40.7 \%$ of them did not seek ANC services. This is a very worrying trend, dangerous and retrogressive. This should not be allowed

\section{5 | CONCLUSION:}

The findings have revealed that the literacy levels especially of the women is quite important in the making of a community, even though both sexes play an important part in passing education down their generations. This has led them to live in ignorance hence a lot of things are lagging behind. Lack of literacy and information on pertinent issues of family care has led to increased numbers of children by birth which directly impacts on the overall population.

Lack of financial capacity and economic empowerment could be part of the reasons to poor food security in the area. This is dangerous as it is an indicator of ill-health in the community. This automatically leads to starvation and under nutrition of both the young and grown-ups thereby causing a recipe for ill health.

The report also showed that, half of the women in Migori County do not visit the health facilities avail- 
able in the county. This is in spite of the Government providing health resources in the region. The reason for such an action is not known, hence the need for more action.

\section{6 | RECOMMENDATIONS:}

In order to make Migori County food secure, the agricultural ministry should intervene with the help of the extension workers and move to educate farmers on the best practices to cub the situation. In addition the government should subsidize agricultural inputs to an affordable rate where the poor farmers should be able to purchase for increased productivity.

Agriculture extension officers should ensure appropriate training of farmers is undertaken to enhance adequate food production and food security.

Community health workers should be instrumental in encouraging the mothers to register as this will help the government when budgeting and planning for interventions.

On literacy levels, the government should move very fast to save the situation since in the near future there may be many people with only primary level education due to high cost of living brought about by rise in prices of essential services and commodities.

There is also need to educate the mothers on family care and the importance of planning the number of children they need to have. The fewer the numbers the better the standard of living and care.

\section{7 | ACKNOWLEDGEMENTS:}

I would like to thank my immediate supervisors who are the Director of Clinical Medicine Dr Andrew
Otieno and the Head of Department in Community Health M/s Pamela for giving me an opportunity to go out to the field. My sincere appreciations go to the Uzima University fraternity led by Principle Father/Rev./Dr Cosmas K'otieno Raggot, the Deputy Principle and Dean in the Medical school Prof Richard Muga, the Registrar Academics and Administration Father/Rev Caroly Achok all for their invaluable support from the time I started studying for this administrative program. These special thanks go to Mildmay International and all its staff especially those who were my lecturers led by Lect Elias Ooko and John Rotich for their distinguished service in the delivery of their units and ensuring the students safety and proper timely provision of all that was required to finish this study.

\section{REFERENCES}

1. Kenya Demographic and Health Survey; 2008-09

2. Kenya Facts and Figures; Kenya National Bureau of Statistics, 2009

3. Population Handbook 5th Edition; Population Reference Bureau, 2004

4. Migori County Development Plan 2009-2011

5. Migori County Development Plan 2009-2011

How to cite this article: Kagoiyo N.S., Wanjiku M.S., Kagoiyo S.W. Evidence Based Health Demographic Assessment of Uriri Sub-County in Migori County, Kenya. Journal of Current Medical Research and Opinion . 2020;1-8. https://doi.org/10.15520/jcmro.v3i08.325 